\title{
CORRESPONDENCE
}

\section{Natural Units}

SIR,-McWeeny ${ }^{1}$ proposes the following abbreviations: as, aV and a $\mathrm{T}$, meaning respectively atomic second, volt and tesla. It should be pointed out, however, that in the SI the prefix atto with the abbreviation a is already in use with the meaning $10^{-18}$, that is 1 as $=10^{-18} \mathrm{~s}$, whereas according to McWeeny its meaning should be $24.19 \times 10^{-18} \mathrm{~s}$. Clearly there might be confusion in this case. With the other units confusion is less likely, as they differ by a factor larger than $10^{19}$. The prefix atto and its abbreviation have been recognized by various standardizing organizations and widely published ${ }^{2}$, although admittedly they are so far not often met with in the literature.

There are two ways of avoiding this conflict. One is simply to use another prefix which when abbreviated would not conflict with SI. One possibility is sysa, abbreviated s (or possibly sy). This prefix is derived from "système atomique", and hence would convey the same meaning as the original proposal. I hope the English-speaking readership will forgive the use of French in this case ( $c f$. Système International des Unités). If there are serious arguments against this prefix, other non-conflicting alternatives may be found (for example wadi, abbreviated w, from "world of atomic dimensions").

Another, perhaps preferable, way of avoiding this conflict is to name a few more units after researchers of outstanding merit. Why not reintroduce the Rutherford ( $R$ or $R u$ ) as the natural time unit, as the old meaning as a unit of radioactivity now may be considered obsolete? In case of doubt, the time unit might be called a Rutherford-second with the same abbreviation (whereas the radioactivity unit was abbreviated rd). Furthermore, Zeeman (Z) might be used in the sense of "atomic tesla" $\left(\hbar / \mathrm{ea}_{0}{ }^{2}\right)$. For "atomic volt" perhaps no new name is needed, since it may so easily be written in the form $\mathrm{Ha} / \mathrm{e}$ (hartree per electron; or per elementary charge). Here I have abbreviated hartree as $\mathrm{Ha}$, considering that $\mathrm{H}$ is the accepted abbreviation of the SI unit henry.

These proposals would retain all the advantages of the system described by McWeeny, but avoid the conflict with
SI and its standardized abbreviations. Yours faithfully, BJøRN E. BøRDALEN

Central Institute for Industrial Research, Oslo-Blindern, Norway

1 McWeeny, R., Nature, 243, 196 (1973).

2 McGlashan, M. L., in Kirk-Othmer Encyclopedia of Chemical Technology, second ed. (edit. by Standen, A.), Suppl., 984 (Interscience, New York, London, Sydney, and Toronto, 1971).

\section{Turning the Cheek}

SIR,-While reading the interesting article by McManus and Humphrey ${ }^{1}$ I was surprised to see that they do not mention the argument that right-handed painters, like right-handed writers, prefer to have the window or any other light source on their left. The subject will then be illuminated from his or her right hand side, and shadows on his left side will be more pronounced if he puts his right cheek forward than when his left cheek confronts the artist. Preference for a clearly delineated or a more gentle portrait might thus provide the answer to the authors' question, and also explain why the bias is strongest for female subjects.

\section{Yours faithfully,}

ZWO,

$$
\text { J. H. BANNIER }
$$

Postbus 2138,

's-Gravenhage

1 Nature, 243, 271 (1973).

\section{John Milne}

SIR,-We are researching the life and work of Professor John Milne (1850 1913), the father of seismology, who was born at Liverpool and died at Shide, Isle of Wight. We are anxious to obtain information about his life, work in Japan, photographic material, personal papers and relatives which will enable us to complete a comprehensive study of this famous but forgotten man. All material loaned will be carefully handled, documented, returned and acknowledged.

$$
\begin{aligned}
& \text { Yours faithfully, } \\
& \text { Leslie Herbert-Gustar } \\
& \text { PATrick A. NotT }
\end{aligned}
$$

Isle of Wight Technical College, Newport, Isle of Wight PO30 5TA

\section{Chromatography Priority}

SIR,--Your correspondent (Nature new Biol., 243, 130 ; 1973) attributes the inception of affinity chromatography in enzyme purification to Cuatrecasas, Wilchek and Anfinsen (Proc. natn. Acad. Sci. U.S.A., 61, 636 ; 1968). May I note that these workers credit Lerman (Proc. natn. Acad. Sci. U.S.A., 39, 232 ; 1953) and Arsenis and McCormick (J. biol. Chem., 239, 3093; 1964) with prior attention to this technique?

Yours faithfully,

Robert F. B. Diller

Baylor College of Medicine,

Texas Medical Center,

Houston, Texas 77025

\section{Mental Illness}

SIR,-Professor Szasz's reasoning (Nature, 242, 305; 1973) is incontestable. However, the premise-that the doctor-patient relationship is a closed system-should not pass without comment.

The doctor, who is also a citizen, has obligations to society; and his philosophy should embrace not only the privacy of his patient but also the circumstances which gave rise to the patient's condition. Consequently the plausible argument, which is superficially sound, is philosophically worthless. It betrays an inability to accept or even acknowledge any whit of humanism beyond the doctor's sworn commitment to his immediate patient.

The laboratory chemist no longer ignores industrial pollution; nor does the physicist radioactive fallout. The doctor too must face up to the wider implications of his special knowledge. The patient's disease should prompt the doctor's concern for public health; mutilation should evoke a desire to avert the carnage, on battlefield or highway ; loss of self-confidence or "mental illness" should foster inquiry into stress ; and incarceration should pose questions of ethics and economics.

Yours faithfully, Douglas H. Ratcliffe

108 Waratah Avenue,

Dalkeith,

Western Australia 6009 